\title{
MULHERES QUEBRADEIRAS DE COCO BABAÇU E MOVIMENTOS SOCIAIS
}

\author{
Leididaina Araújo e Silva \\ Bibliotecária do Ministério Público Estadual do Amapá \\ leididaina@gmail.com
}

\begin{abstract}
Resumo
O artigo aborda o trabalho as mulheres quebradeiras de coco babaçu integrantes do Movimento Interestadual das Quebradeiras de Coco Babaçu (MIQCB), movimento concebido, fundado e liderado por camponesas extrativistas. O movimento existe há mais de 23 anos e se organiza em quatro estados da federação (dois da região Nordeste Maranhão e Piauí - e dois da região Norte - Pará e Tocantins). A partir de um resgaste histórico de alguns movimentos sociais de trabalhadores rurais no Brasil, Movimento de Mulheres Camponesas (MMC), Movimento de Mulheres Trabalhadoras Rurais (MMTR), Movimento de Mulheres Agricultoras (MMA), entre outros, destacando o protagonismo das mulheres camponesas na luta pelos seus direitos. Metodologicamente, trata-se de um estudo qualitativo. Observou-se que a década de 80 foi uma década ímpar no que diz respeito ao despertar das mulheres do campo para as lutas e reivindicações de seus direitos individuais e coletivos. Conclui-se que, as mulheres que compõem os diversos movimentos sociais, se consideram fortalecidas enquanto sujeitos políticos e representantes dos movimentos femininos; seus trabalhos são reconhecidos e valorizados dentro do contexto social e político em que estão inseridas.
\end{abstract}

Palavras-chave: Gênero. Mulheres quebradeiras de coco babaçu. Trabalhadoras rurais. Movimentos sociais.

\section{BABASSU COCONUT BREAKING WOMEN AND SOCIAL MOVEMENTS}

\begin{abstract}
The article to approach women the bagasse coconut breaking that are part of the Coco Babassu Intersection Movement (MIQCB), a movement conceived, founded and led by extractivist peasants. The movement has existed for more than 23 years and is organized in four states of the federation (two from the Northeast - Maranhão and Piauí - and two from the North - Pará and Tocantins). It makes a historical recovery of some social movements of rural workers in Brazil, the Movement of Rural Women (MMC), the Movement of Rural Women Workers (MMTR), the Movement of Women Farmers (MMA), among others, highlighting the role of peasant women in the struggle for their rights. Methodologically, this is a qualitative study. It was observed that the 1980s was an unparalleled decade regarding the awakening of rural women to the struggles and claims of their individual and collective rights. It is concluded that the women who make up the various social movements consider themselves strengthened as subjects and as representatives of women's movements; That their work is recognized and valued within the social and political context in which they are inserted.
\end{abstract}

Keywords: Gender. Women babaçu cocou breaking. Rural Works. Social movements.

\section{INTRODUÇÃO}

O Movimento Interestadual das Quebradeiras de Coco Babaçu (MIQCB) teve início nos últimos anos da década de 80 do século XX após diversos conflitos em terras maranhenses,

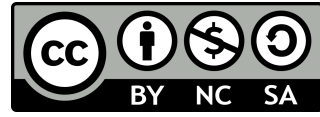


mais precisamente na região conhecida como Médio Mearim ${ }^{1}$. O estopim para os diversos conflitos pela posse de terras - conforme Almeida (1995), Shiraishi Neto (2005) e Barbosa (2007) explicitam - se deu com a aprovação da Lei n. 2.979/17, de 17 de julho de 1969, conhecida como "Lei Sarney de Terra". Essa lei dava respaldo legal à privatização das terras públicas do Estado do Maranhão e incentivava os projetos agropecuários e agroindustriais, limitando o acesso das famílias rurais a áreas de babaçuais.

Os trabalhadores rurais, e mais precisamente as quebradeiras de coco babaçu que viviam do extrativismo, com tinham livre acesso às áreas de babaçuais, foram prejudicados e decidiram reagir. A partir daí muitas mulheres que já participavam de grupos organizados pela Igreja Católica - como os clubes de mães, os grupos de jovens, as Comunidades Eclesiais de Base (CEBs), os grupos de trabalhos organizados, como é o caso das quebradeiras que saíam em grupos para realizarem o trabalho da quebra do coco babaçu dentro das matas de babaçuais - criam a Associação de Mulheres Quebradeiras de Coco Babaçu (AMQCB). Conforme Maria Adelina Chagas, uma das fundadoras do movimento, somente em 1991 essa associação veio a ser oficializada durante o primeiro Encontro Interestadual do Movimento das Quebradeiras de Coco, tendo reunido, na oportunidade, cerca de 250 mulheres (quebradeiras de coco, castanheiras, agricultoras, lavradoras, rendeiras, etc.). A partir de 1995 a associação passou a se chamar oficialmente Movimento Interestadual das Quebradeiras de Coco Babaçu - MIQCB (CHAGAS apud BARBOSA, 2007).

Considerando que movimentos sociais, assim como o das quebradeiras de coco aqui mencionado, resultam de um constructo de informações regionais e locais, as quais representam a sua história, nossa atenção também se voltou para a diversidade e abrangência dos movimentos sociais criados por mulheres de norte a sul do Brasil, tais como o Movimento de Mulheres Camponesas, (MMC) que hoje é mais consolidado no Sul, e o Movimento de Mulheres Trabalhadoras Rurais (MMTR), que se encontra consolidado em todo o Brasil só que sendo mais forte no Nordeste. Destacamos também questões relacionadas ao uso da informação, acesso e uso das TIC, além de questões relacionadas às desigualdades de gênero, étnico-raciais e empoderamento das trabalhadoras rurais, isto é, aqui tratamos com grupos e indivíduos pertencentes às classes menos favorecidas social, geográfica e economicamente.

Como referencial teórico utilizamos alguns autores/pesquisadores que desenvolveram e desenvolvem pesquisas abordando as questões de gênero e trabalho, gênero e informação, notadamente o uso das TIC para o empoderamento dos grupos em desvantagem social e das

\footnotetext{
${ }^{1}$ Uma microrregião localizada no centro do Estado do Maranhão que contempla 21 municípios.
} 
mulheres. Dentre os quais destaca-se Logan (2012), Veloso (2011), Albagli e Maciel (2011), González de Gómez (2011), Bourdieu (2012) D’Araujo (2003), Antunes (2006), Sales (2007) e Olinto e Oliveira (2004). O levantamento e a análise da literatura sobre o próprio MIQCB será também um dos pontos destacados neste estudo.

\section{QUEBRADEIRAS DE COCO BABAÇU E MOVIMENTOS SOCIAIS}

O estudo trata das quebradeiras de coco babaçu, integrantes do MIQCB, movimento de mulheres camponesas bem-sucedido, resultante da iniciativa de organização de uma atividade econômica inserida em contexto de pobreza extrema, no meio rural das regiões Norte e Nordeste do Brasil, com indicadores econômicos e sociais precários e, além disso, basicamente executada por um segmento também socialmente e economicamente desprivilegiado: as mulheres. Bem como, outros movimentos sociais protagonizado por trabalhadores rurais, especialmente por mulheres. Trata-se, portanto, de uma reação a uma situação em que se sobrepõem condições de desigualdades: desigualdades econômicas-sociais e desigualdades de gênero e no trabalho. Consideramos que a descrição e análise de recursos informacionais utilizados nesses movimentos podem contribuir para identificação de processos que favorecem a superação dessas diversas desigualdades que afetam as mulheres na contemporaneidade.

De certa forma, podemos considerar que a inserção das trabalhadoras rurais nos movimentos sociais contribuiu para o amadurecimento destas enquanto sujeito político e social, rompendo sua invisibilidade como trabalhadora. Ressaltamos a década de 80 como marco para o despertar das mulheres para as lutas sociais e políticas em busca de seus direitos, como destaca Sales (2007). Segundo a autora, na segunda metade da década de 80, a luta das trabalhadoras rurais abre novos espaços políticos. Naquela época, as principais reivindicações das mulheres eram pela sindicalização, documentação e participação política. A autora comenta ainda que os anos 90 foram um período de adesão às discussões sobre desigualdades de gênero, a exemplo da Igreja Católica que teve sua campanha da Fraternidade de 1990 com o seguinte tema: "Deus quer homem e mulher como companheiros, iguais nos direitos porque os dois são imagem e semelhança d'Ele". Esta campanha foi um incentivo ao debate sobre a condição da mulher, tanto no campo como na cidade.

Em estudo realizado no Ceará sobre a questão do trabalho da mulher no campo, Sales (2007) afirma que as organizações de trabalhadoras rurais do Ceará estimulam suas lideranças a pensarem sobre as desigualdades de gênero, e a partir desse olhar, as trabalhadoras começam a discutir sobre a invisibilidade do seu trabalho na agricultura familiar camponesa. Através 
dessas organizações, as trabalhadoras rurais são levadas a adquirir consciência de que as atividades produtivas desenvolvidas no grupo familiar têm um significado econômico importante; não sendo simplesmente uma "ajuda" como seus companheiros tendem a classificar.

Também contribuíram para o empoderamento, para a mudança de comportamento e para a atuação organizada da mulher no meio rural brasileiro, alguns movimentos sociais de destaque e grande repercussão, notadamente o Movimento de Mulheres Camponesas (MMC) e o Movimento de Mulheres Trabalhadoras Rurais (MMTR), são movimentos que certamente tiveram influência na formação do MIQCB.

O MMC e o MMTR abrangem diversas regiões do Brasil, estando ainda presentes em vários estados brasileiros, sendo que o MMC é mais consolidado nas regiões Sul e Sudeste e por sua vez o MMTR nas regiões Norte e Nordeste. A importância desses dois movimentos é destacada pelo Dossiê "Mulheres e meio ambiente" publicado no ano de 2010 no periódico "Revista Estudos Feministas."

O referido dossiê traz abordagens sobre mulheres protagonistas em questões ambientais, políticas e sociais, além de fazer remissivas a outros importantes trabalhos sobre meio ambiente, na perspectiva das mulheres ("Memórias do Planeta Fêmea"; "Ecos feminismos, na ECO-92"; "Desenvolvimento sustentável com a perspectiva de gênero - Brasil, México e Cuba: mulheres protagonistas no meio rural"; "A construção de uma agenda para as questões de gênero, desastres socioambientais e desenvolvimento"; "Mulheres da floresta do Vale do Guaporé e suas interações com o meio ambiente" e "Intelectuais \& militantes e as possibilidades de diálogo"). Para compreender os referidos movimentos foram analisados estudos (entre artigos, dossiês, resenhas, ensaio e ponto de vista) publicados em periódicos nacionais (principalmente no periódico "Revista Estudos Feministas"). Tais estudos foram realizados entre os anos de 1992 a 2013.

Brumer e Paulilo (2004) consideram que o MMC decorre do Movimento de Mulheres Agricultoras (MMA) criado na década de 1980 no Estado de Santa Catarina. Porém, foi apenas em 2004 que o MMC Brasil se consolidou, unificando vários grupos estaduais (BOSETTI, 2010). Atualmente o MMC se organiza em dezoito estados brasileiros, sendo que sua instância máxima de decisões é o congresso nacional que acontece a cada três anos. Seu escritório tem sede em Brasília e sua Secretaria Nacional na cidade de Passo Fundo no Rio Grande do Sul.

Percebemos na literatura que uma pergunta é recorrente ao MMC. Por que a mudança de nomenclatura, em 2004, para MMC, se o movimento já era conhecido e consolidado

\footnotetext{
2 O periódico "Revista Estudos Feministas" é sediado no
} 
nacionalmente como MMTR? Quem responde a questão é uma militante/liderança do movimento. Segundo ela, a explicação é que “[...] a palavra camponês se refere a todos que estão no campo: produtores rurais, meeiros, agregados, quebradeiras de coco, cortadores de cana, etc." (PAULILO; SILVA, 2007). Ou seja, o termo camponês abrange um universo maior de pessoas - todos aqueles que estão vivendo ou trabalhando no campo -, não se restringindo apenas às pessoas que lutam por um pedaço de terra.

Nos anos finais da década de 1980 vários MMTRs estaduais foram surgindo e, com isso, houve um crescimento da participação de mulheres no movimento sindicalista rural. De acordo com Deere (2004) as raízes do Movimento de Mulheres Trabalhadoras Rurais no Nordeste (MMTR-NE) se deu em reuniões realizadas nos municípios de Brejo, Paraíba e Serra Tablada no Sertão Central, no estado de Pernambuco. Isso se deu entre os anos de 1982 e 1983. O motivo das reuniões era discutir uma seca prolongada que vinha assolando a região. Após essas reuniões, oficialmente em 1984, foi fundado o Movimento de Mulheres Trabalhadoras Rurais do Sertão Central - que além dos problemas com a seca também trazia a necessidade de aumentar a participação das mulheres trabalhadoras rurais nos movimentos sindicalistas.

Segundo Brumer e Paulilo (2001), data de 1989 o surgimento do Movimento de Mulheres Trabalhadoras Rurais no Rio Grande do Sul (MMTR-RS), e pelos relatos, esse foi um movimento que já nasceu fortalecido em quantidade: na ocasião do seu surgimento o movimento contou com cerca de 500 militantes, sendo que muitas delas já dispunham de experiências anteriores com atividades que realizavam em igrejas, sindicatos, etc.

O MMTR está presente nos nove estados da Região Nordeste, bem como em outros estados brasileiros. De acordo com Cordeiro e Scott (2007), no Norte e Nordeste, as ações políticas das mulheres nos contextos rurais contemplam uma agenda bastante ampla, além das questões agrárias, trabalhistas e previdenciárias, as mulheres realizam encontros, seminários e oficinas sobre violência, saúde, geração de renda, meio ambiente, direitos sexuais e reprodutivos, entre outros temas. Tal pensamento reforça a ideia de que as mulheres camponesas que participam desses movimentos estão cientes sobre seus direitos e deveres enquanto cidadãs brasileiras, e que o fato de morarem no campo e assumirem uma identidade camponesa nem sempre as deixam alienadas quanto as reivindicações desses direitos.

Conforme apresentação do MMC e do MMTR, a década de 80 foi uma década ímpar no que diz respeito ao despertar das mulheres do campo para as lutas e reivindicações de seus direitos individuais e coletivos. Ou seja, durante toda a década de 80 vários MMCs e MMTRs foram fundados. Por conta disso, nos anos iniciais da década de 90 houve esforços para unificar esses movimentos estaduais em uma aliança nacional. Conforme Lisboa e Lusa (2010) em 1995 
por meio da Articulação Nacional de Mulheres Trabalhadoras Rurais (ANMTR) alcançou-se o tão almejado objetivo de formar uma aliança nacional. Hoje a ANMTR é formada pelos MMTRs estaduais e agrega outros movimentos, associações, órgãos, instituições e entidades, tais como: Movimento dos Pequenos Agricultores (MPA), a Comissão Pastoral da Terra (CPT), Movimento dos Atingidos por Barragens (MAB) e Movimento dos Trabalhadores Rurais (MST), entre outros. Ressaltando que todos aqui citados estão engajados nas lutas pelo campo, pela terra.

Vale destacar ainda, que no contexto internacional a ANMTR é membro da Via Campesina $^{3}$ e da Coordenadoria Latino-Americana de Organizações do Campo (CLOC). No ano de 1997, a ANMTR lançou uma importante campanha em âmbito nacional, intitulada "Nenhuma trabalhadora rural sem documentos", na qual foram distribuídas cartilhas de informação/formação em vinte e um estados brasileiros. O objetivo da campanha era fazer com que todas as trabalhadoras rurais regularizassem seus documentos pessoais e profissionais, ou seja, saíssem do anonimato e passassem a existir legalmente perante a sociedade.

Convém mencionar também as palavras de Sales (2007), quando aponta que somente no ano de 1985 ocorreram 12 encontros de mulheres trabalhadoras rurais nas mais diversas regiões do país. E que em novembro de 1986, as mulheres rurais realizaram em Brasília o primeiro Encontro Nacional de Trabalhadoras Rurais. A partir dessas informações podemos perceber quão forte foram os movimentos surgidos na década de 1980. Além do MMC e MMTR e da já mencionada Articulação Nacional de Mulheres Trabalhadoras Rurais (ANMTR) podem ser citados outros importantes movimentos, associações, órgãos, instituições e entidades de mulheres trabalhadoras rurais/camponesas, tais como: Movimento de Mulheres Agricultoras (MMA), Movimento dos Pequenos Agricultores (MPA), Movimento dos Atingidos por Barragens (MAB), Coordenadoria Latino-Americana de Organizações do Campo (CLOC), Coletivos Estaduais de Mulheres (CEM), Federações de Trabalhadores Rurais dos Estados (FTRE), Rede de Mulheres Trabalhadoras do Nordeste (RMT-NE), Movimento Interestadual das Quebradeiras de Coco Babaçu (MIQCB) e a Via Campesina.

Levando em consideração a literatura consultada é possível afirmar que foi a partir do início da década de 80, do século XX, que vários movimentos autônomos de mulheres surgiram e se fortaleceram com lutas em prol dos direitos sociais e individuais das mulheres camponesas. Nas diversas lutas travadas a partir de 1980, destacam-se as seguintes reivindicações: pelo 
reconhecimento profissional da trabalhadora rural, pela participação sindical, pelo direito a terra e a reforma agrária, pela licença maternidade remunerada e aposentadoria para as mulheres trabalhadoras rurais, entre outras.

Não podemos deixar de citar também neste capítulo um movimento que nasceu e se consolidou um pouco antes da década de 1980: o Movimento dos Trabalhadores Sem Terra (MST). O MST surgiu no final da década de 1970, no Sul do Brasil, e tem (dentre as suas várias bandeiras de luta) na luta pela reforma agrária - com a reivindicação por divisão mais igualitária das terras - sua razão de ser. Este movimento sempre lutou contra as injustiças do sistema de posse de terra tradicional, em que muitas terras permanecem nas mãos de poucos. Vale ressaltar que a criação do MST, e início de sua luta pela reforma agrária no Brasil, iniciou-se nos primeiros anos da década de 1960, período de transição e de muitos conflitos, pois neste mesmo período (1964-1985) deu-se início a ditadura militar no país.

Devido à grande pressão dos movimentos de mulheres da década de 1980 em todo o país, a Constituição Federal de 1988 reconheceu a categoria de produtoras rurais. E mais, esse reconhecimento veio acompanhado de garantias às mulheres dos seus direitos previdenciários, tais como: aposentadoria aos 55 anos para as trabalhadoras rurais e licença-maternidade remunerada, benefícios antes concedidos apenas às trabalhadoras urbanas (BRUMER; PAULILO, 2004).

\subsection{Mulheres, informação e empoderamento}

Apesar da Constituição Federal de 1988 ter reconhecido a igualdade entre homens e mulheres na família e de ter estabelecido igualdade de direitos entre ambos na obtenção de títulos de domínio, ou de concessão, de uso de terras para fins de reforma agrária, as mulheres ainda enfrentam obstáculos neste processo. Obstáculos como, por exemplo, a falta de documentos - principalmente em contextos de baixo nível de instrução e escolaridade, o que as impossibilita de lidar com atividades como abrir conta bancária, ler e assinar documentos, por exemplo.

O reconhecimento legal das mulheres na produção da agricultura familiar foi um grande passo, mas além das leis se faz necessário um conjunto de ações paralelas que empoderem as mulheres. Para que elas possam, de fato, usufruir dos direitos conquistados. Reconhece-se que ainda é grande a burocratização que envolve os programas de crédito, o que dificulta o acesso das mulheres a esses programas.

Para a superação dessas desigualdades de gênero a contribuição das novas 
Tecnologias de Informação e Comunicação (TIC), tende a ser reconhecida como um recurso importante na atualidade. Para Logan (2012), é difícil contestar que vivemos a era da informação, bem como a existência de uma vasta gama de tecnologias à disposição para gerar, comunicar, interpretar e explorar a informação. Para Veloso (2011), a apropriação das TIC em processos de trabalho pode assumir um caráter estratégico, possibilitando melhorias e avanços significativos nas diversas práticas às quais este recurso pode ser incorporado, proporcionando dentre outros fatores, a viabilização de avanços na luta pela defesa de direitos, pela ampliação e consolidação da cidadania e pelo aprofundamento da democracia.

As TIC potencializam a constituição de redes que conectam ideias, experiências, sujeitos e instituições; os quais organizados a partir de relações horizontais, desencadeiam fluxos de interações, organizações, produções, conhecimentos, competências e aprendizagens (BONILA, 2005 apud VELOSO, 2011). Sendo assim, as TIC podem contribuir para a diminuição das desigualdades sociais. Trata-se de um potencial estratégico que pode se voltar, não apenas para os interesses dos segmentos dominantes da sociedade, mas também contribuir para a construção de um projeto de sociedade que confere prioridade às demandas provenientes dos segmentos majoritários da população.

Segundo Albagli e Maciel (2011) há quem dê ênfase a novas desigualdades sociais e econômicas associadas a difusão das tecnologias de informação e comunicação (TIC). Entretanto, segundo as autoras, grande parte da literatura enfatiza positivamente o papel atual dos espaços digitais - como ambientes propícios à comunicação da informação em rede, para a difusão e adoção de formas e estratégias de produção e colaboração social não proprietários, não mercantis, com maior autonomia dos participantes e em formatos não necessariamente estruturados e hierarquizados.

Para González de Gómez (2006, p. 29), “[...] as mudanças do papel do conhecimento, da comunicação e da informação no mundo contemporâneo, propiciaram um rico espaço intermediário no qual estudiosos das ciências do conhecimento, da linguagem e da informação encontraram-se lado a lado na construção de seus objetos [...]". Neste contexto, estudiosos da economia, da política e da sociologia, convergem na demanda por novos esforços e entendimentos, novas questões e possibilidades importantes para serem elucidadas. Ainda, segundo a autora, em diferentes momentos a informação foi tematizada como expressão de um domínio em que alguns dos principais problemas de integração das sociedades modernas, envolvendo intercâmbio de conhecimentos, de práticas de pesquisa, de meios e linguagens seriam resolvidos.

Nos auxilia em muito trazer à discussão o conceito de capital social. Para Bourdieu 
(2012) o capital social representa um conjunto de recursos atuais ou potenciais que estão ligados a posse de uma rede durável de relações mais ou menos institucionalizadas de interconhecimento e de inter-reconhecimento ou, em outros termos, à vinculação em um grupo, como conjunto de agentes que não somente são dotados de propriedades comuns, mas também são unidos por ligações permanentes e úteis. Vale ressaltar que para autores como Putnam, Coleman e Bourdieu, o capital social, baseado na interação dentro de grupos, ou entre grupos, é elemento básico da democracia e da cidadania, sendo capaz de promover a confiança mútua e o desenvolvimento de comunidades.

Para D’Araujo (2003), capital social reflete uma maneira integrada de agir e de interagir que têm na confiança e na cooperação as moedas da boa sociedade. Corroborando neste sentido, temos Junqueira e Trez (2005), que consideram que o capital social e a cultura são formados a partir das pessoas, das famílias e dos grupos; ou seja, onde estão presentes os conceitos de cooperação, confiança, identidade, comunidade e amizade.

O tema capital social tem sido constantemente abordado em diversas áreas do conhecimento. Conforme Olinto e Medeiros (2013), temas bastante distintos como as relações de poder, as desigualdades sociais, o desenvolvimento comunitário e a inovação em processos econômicos e organizacionais têm sido abordados pela ótica de capital social. No entanto, o capital social ainda não tem sido tematizado em estudos sobre benefícios que possam trazer para os movimentos de mulheres.

Para Antunes (2006) o tortuoso caminho de empoderamento trilhado pelas quebradeiras de coco babaçu nas esferas sociais, políticas e econômicas produziu conquistas importantes que melhoraram a vida daquelas mulheres. No Maranhão o MIQCB levou as mulheres trabalhadoras rurais a se fortalecer como grupo, a enfrentarem seus maridos/companheiros em busca de empoderamento e de autonomia, indo à luta nos babaçuais e nos conflitos pela terra. Vale frisar que esse processo de lutas teve início com a participação das mulheres nos clubes de mães e nos grupos de quebra de coco coletiva.

Essas conquistas não envolvem, necessariamente, todos os aspectos da vida dessas mulheres. Conforme Antunes (2006), algumas tornam-se lideranças empoderadas e esposas desempoderadas, sendo essa a estranha história de algumas quebradeiras de coco babaçu. Parece que essas mulheres mudam de papéis ao entrarem em suas casas, deixando todo o poder alcançado na esfera coletiva do lado de fora. É triste essa realidade, mas é o que conseguimos perceber na literatura que aborda esses processos de lutas das mulheres quebradeiras de coco babaçu. O empoderamento ainda é uma conquista de poucas e ganha diferentes contornos conforme a esferas da vida social em questão. Essa realidade não deixa de trazer ranços do 
patriarcalismo, ainda muito presente nas regiões Norte e Nordeste, especialmente no meio rural.

2.1 As desigualdades sofridas pelas mulheres no meio rural: ranço do patriarcalismo

Ao que consta na literatura o ranço do patriarcalismo no meio rural ainda se faz presente. Bursztyn (2008, p. 41) ressalta que "[...] é a partir das relações patriarcalistas da sociedade patriarcal que a estrutura social rural se constitui. $\mathrm{O}$ patriarcalismo se torna um mecanismo ideológico e social fundamental para contrabalançar o autoritarismo tanto do Estado como do patriarca local. " O que vale para o meio rural em geral, como explicitado, também se aplica a comunidades rurais do Norte e Nordeste do país. Diante dessas relações sociais desfavoráveis às mulheres torna-se difícil a sua luta por mais autonomia, pelo reconhecimento profissional, por igualdade de gênero e, consequentemente, empoderamento. Tais lutas objetivam romper com esse modelo de sociedade, onde o homem deve ser o único provedor do lar, e cuja autoridade define as relações familiares, assim como relações sociais e políticas em geral.

Segundo Albuquerque Junior (2013, p. 125), Gilberto Freyre propôs o uso do conceito de família patriarcal “[...] para descrever as relações familiares no Brasil, desde o período colonial até o final do século XIX, quando esta teria entrado em declínio, para ser substituída paulatinamente pela família nuclear burguesa [...]”. Para o autor, o conceito de patriarcalismo em Freyre não pretende apenas descrever um modelo de família ou forma de relação entre gêneros, ele tem a pretensão de descrever toda uma ordem social, na qual o poder patriarcal e a família seriam os elementos nucleares.

O patriarcalismo, sociedade do poder masculino, do império dos pais, assentada em relações paternalistas, de filhotismo e apadrinhamento, sociedade das parentelas, ia sendo modificada por um processo que é visto como de desvirilização, de declínio de um modelo de masculinidade, período de confusão entre as fronteiras de gêneros, em que as mulheres precisam assumir lugares antes reservados aos homens. (ALBUQUERQUE JUNIOR, 2013, p. $130)$.

Historicamente, a divisão de trabalho numa perspectiva de gênero sempre existiu. As mulheres sempre foram associadas à reprodução e aos afazeres domésticos. Os homens estiveram sempre relacionados ao trabalho fora de casa e sendo vistos como os provedores da família. [à mulher caberia, então, o espaço privado, enquanto para o homem caberia o espaço público].

Este tipo de análise se adéqua às características do trabalho das mulheres quebradeiras 
de coco. Barbosa (2005) ressalta que a idealização do homem como chefe de família e, portanto, provedor, contribui para que a renda feminina do extrativismo seja vista apenas como uma mera ajuda na manutenção familiar.

Conforme estudo de Olinto e Oliveira (2004), a proporção de mulheres na categoria trabalho informal é bastante considerável no Brasil e muito superior à dos homens, o que reflete diretamente na invisibilidade do trabalho da mulher e em sua participação na economia brasileira. As autoras ressaltam ainda que as diferenças salariais entre gêneros tende a ser maior entre os que trabalham na categoria de trabalho informal. Isso ocorre principalmente quando esse trabalho informal é exercido no ambiente doméstico, pois este tende a se misturar a atividades que as mulheres já desenvolvem em suas residências.

Neves (2011) de acordo com a Organização Internacional do Trabalho - OIT, relata que as desigualdades das mulheres no mercado persistem, pois existe um forte contingente feminino concentrado nas atividades de serviços precarizados, recebendo remunerações mais baixas, principalmente no trabalho doméstico. Ainda de acordo com a OIT, o trabalho das mulheres desenvolvido no ambiente doméstico é caracterizado por baixa proteção salarial e condições inadequadas de trabalho. Para a referida organização, a igualdade de gênero é uma questão de justiça social e se funda nos campos dos direitos e da eficiência econômica. Quando todos os atores da sociedade podem participar formalmente do trabalho aumentam as possibilidades de alcançar justiça social, crescimento econômico e desenvolvimento.

Nesse sentido, Melo e Sabbato (2011), ressaltam que não se pode ignorar as grandes conquistas da mulher na contemporaneidade: o século XX registrou mudanças significativas na sociedade, relativas à inserção crescente das mulheres no mercado de trabalho e nos espaços de poder. Os autores consideram, no entanto, que é importante assinalar que essa mulher "emergente" ainda mantém uma interdependência entre vida familiar e vida do trabalho, que se fundem numa mesma dinâmica. Essa dinâmica para o sexo feminino não é vivida pela maioria dos homens. Essa evidência remete, por sua vez, as denúncias feitas pelos movimentos de mulheres sobre a invisibilidade do trabalho feminino e sobre as desigualdades que caracterizam sua inserção produtiva: rendimentos inferiores, direitos previdenciários negados, obstáculos aos planos de ascensão a cargos de chefias, etc. É nesse sentido que o invisível é desvendado no plano simbólico, quando se caracterizam os afazeres domésticos como trabalho complementar, acessório e de ajuda.

Para Faria (2011), o debate sobre a autonomia econômica das mulheres traz elementos recorrentes e referentes à desigualdade de acesso à renda, à invisibilidade do trabalho de mulheres e ao fato de que elas são as principais responsáveis pelo trabalho doméstico e de 
cuidados com crianças, doentes, idosos, etc. Ainda segundo o autor, nas áreas rurais as relações patriarcais fazem com que a família seja compreendida como um todo homogêneo, em que o homem representa os interesses do conjunto e detém o poder de decisão. Dessa forma, a partir da família, se organiza uma hierarquia de gênero e geração centrada no poder dos homens sobre as mulheres e filhos (as). O rompimento deste status quo deve, para Vera Soares (2011), contar com a contribuição do estado:

Para a construção da igualdade no mercado de trabalho e para o exercício da autonomia das mulheres, se faz necessário uma ação determinada do Estado, criando tanto ações que interfiram diretamente nas relações de trabalho, com políticas ativas de emprego como a inclusão de cláusulas nas negociações coletivas que contemple este princípio. Além disso, é preciso implementar políticas sociais que deem suporte a essa construção. As políticas sociais que pretendem criar condições de igualdade e autonomia nessa área devem incluir medidas destinadas a assegurar que trabalhadores e trabalhadoras tenham facilidades iguais ou equivalentes para formação profissional, treinamento e acesso a empregos e ocupações. (SOARES, 2011, p. 291).

Nesse contexto, o surgimento das cooperativas é especialmente relevante para a valorização das mulheres. Ao referirem-se a este assunto, Lima et al. (2007), mostram o trabalho das mulheres nas cooperativas e associações na região metropolitana de Belém do Pará, através de pesquisa desenvolvida em nove cooperativas. Os autores nos revelam que a maioria dos cooperados são mulheres, [e conclui que isso se deve] o que evidencia que as mesmas ingressam no trabalho associativista devido à dificuldade de se inserirem no mercado de trabalho formal.

Em pesquisa realizada no ano de 2006, Lima et al (2007) entrevistaram 71 membros das cooperativas. Os respondentes ressaltaram a importância do trabalho nas cooperativas como forma de complementar a renda familiar: 64\% das entrevistadas afirmaram que já haviam ingressado no mercado de trabalho antes de ingressar no trabalho em cooperativas. No entanto, as atividades por elas desenvolvidas eram aquelas que não exigiam um maior nível de escolaridade, tais como: faxineira, camareira de hotel, doméstica, promotora de vendas, confecção de bombons, vendedora ambulante, comerciante, cabeleireira, etc.

Em suma, a superação da desigualdade de gênero no acesso ao mercado de trabalho pode ser considerada como intimamente relacionada a um processo mais abrangente de emancipação da mulher envolvendo mudanças profundas nas relações familiares, no acesso a 
informação e empoderamento das mulheres.

\section{CONSIDERAÇÕES FINAIS}

O estudo teve como objetivo abordar o trabalho das mulheres quebradeiras de coco babaçu, integrantes do Movimento Interestadual das Quebradeiras de Coco Babaçu (MIQCB), movimento consolidado e com mais de 23 anos de existência. O MIQCB se organiza em quatro estados da federação (dois da região Nordeste - Maranhão e Piauí - e dois da região Norte Pará e Tocantins). O estudo, objetivou, ainda, apresentar aspectos históricos sobre os movimentos sociais de trabalhadores rurais no Brasil: Movimento de Mulheres Camponesas (MMC), Movimento de Mulheres Trabalhadoras Rurais (MMTR), Movimento de Mulheres Agricultoras (MMA), entre outros, com destaques para as mulheres camponesas que protagonizaram diversas lutas em busca de seus direitos. Com foco na questão da informação e em questões relacionadas à participação e empoderamento dessas mulheres a partir da década de 80. Para tal, realizou-se inicialmente um levantamento de dados históricos e atuais do MIQCB de dos demais movimentos sociais rurais.

Observou-se que apesar da luta incansável das mulheres camponesas quebradeiras de coco babaçu e demais trabalhadoras rurais, elas obtiveram algumas conquistas, destacando trechos da Constituição Federal de 1988 que reconheceu a categoria de produtoras rurais dandolhes algumas garantias e direitos previdenciários, tais como: aposentadoria aos 55 anos para as trabalhadoras rurais e licença-maternidade remunerada. Observou-se ainda, que década de 80 foi uma década ímpar no que diz respeito ao despertar das mulheres do campo para as lutas e reivindicações de seus direitos individuais e coletivos.

Conclui-se que, as mulheres que compõem os diversos movimentos sociais, se consideram fortalecidas enquanto sujeitos e enquanto representantes dos movimentos femininos; que seus trabalhos são reconhecidos e valorizados dentro do contexto social e político em que estão inseridas.

\section{REFERÊNCIAS}

ALMEIDA, Alfredo Wagner Berno de. Quebradeiras de coco babaçu: identidade e mobilização. III Encontro Interestadual das Quebradeiras de Coco Babaçu. São Luís, 1995.

ALBAGLI, Sarita; MACIEL, Maria Lucia. Informação, poder e política: a partir do Sul, para além do Sul. In: Informação, conhecimento e poder: mudança tecnológica e inovação 
social. Maria Lucia Maciel e Sarita Albagli (Org.). Rio de Janeiro: Garamond, 2011.

ALBUQUERQUE JÚNIOR, Durval Muniz de. Nordestino: invenção do "falo": uma história do gênero masculino (1920-1940). São Paulo: Intermeios, 2013.

ANTUNES, Marta. As guardiãs da floresta do babaçu e o tortuoso caminho do empoderamento. In:__. NEAD Especial. Margarida Alves: coletânea sobre estudos rurais e gênero. Ellen F. Woortmann, Renata Menache, Beatriz Heredia (organizadoras). Brasília: MDA, 2006.

BARBOSA, Viviane de Oliveira. Na terra das palmeiras: gênero, trabalho e identidades no universo de quebradeiras de coco babaçu no Maranhão. 2007. Dissertação (Mestrado em Estudos Étnicos e Africanos) - Universidade Federal da Bahia, Salvador, 2007a.

. "Sou quebradeira eu sou! Quebrando coco eu vou! ": movimento social, gênero e identidades. II SEMINÁRIO NACIONAL MOVIMENTO SOCIAIS PARTICIPAÇÃO E DEMOCRACIA. Florianópolis, 2007.

. Na quebra do coco babaçu: gênero, família e trabalho. Ciências Humanas em Revista. v. 3, n. 2. São Luis, 2005.

BOURDIEU, Pierre. O capital social - notas provisórias. In:___ Escritos de Educação. Maria Alice Nogueira e Afrânio Catani (Org.), 13 ed. Petrópolis, RJ: Vozes, 2012. Cap. 3.

Os três estados do capital cultual. In: Escritos de Educação. Maria Alice Nogueira e Afrânio Catani (Org.), 13 ed. Petrópolis, RJ: Vozes, 2012. Cap. 4.

BOSETTI, Cleber José. Movimento das Mulheres Camponesas: identidade, inclusão e projeto político. Anais. III SEMINÁRIO NACIONAL E I SEMINÁRIO INTERNACIONAL: Movimentos Sociais, Participação e Democracia. Florianópolis, 2010.

BRUMER, Anita; PAULILO, Maria Ignez S. As agricultoras do Sul do Brasil. Revista de Estudos Feministas, Florianópolis, 2004.

BURSZTYN, Marcel. O poder dos donos: planejamento e clientelismo no Nordeste. Rio de Janeiro: Garamond, 2008.

CORDEIRO, Rosineide de L. M.; SCOTT, Russel Parry. Mulheres em áreas rurais nas regiões Norte e Nordeste do Brasil. Revista de Estudos Feministas, maio./ago. Florianópolis, 2007.

D’ARAUJO, Maria Celina Soares. Capital social. Rio de Janeiro: Jorge Zahar, 2003.

DEERE, Carmen Diana. Os direitos da mulher a terra e os movimentos sociais rurais na reforma agrária brasileira. Revista de Estudos Feministas, jan./abr. Florianópolis, 2004.

FARIA, Nalu. Desafios para a construção da autonomia econômica para as mulheres. In:_Autonomia econômica e empoderamento da mulher: textos acadêmicos. Brasília: Fundação Alexandre de Gusmão, 2011.

GONZÁLEZ DE GÓMEZ, M. N.. Informação, conhecimento poder: do ponto de vista das relações entre política, economia e linguagem. In: Informação, conhecimento e poder: 
mudança tecnológica e inovação social. Maria Lucia Maciel e Sarita Albagli (Org.). Rio de Janeiro: Garamond, 2011.

JUNQUEIRA, Luciano Antonio Prates; TREZ, Alberto Paschoal. Capital social e a sobrevivência das cooperativas de trabalho. RAP, mar./abr. Rio de Janeiro, 2005.

LISBOA, Teresa Kleba; LUSA, Mailiz Garibotti. Desenvolvimento sustentável com perspectiva de gênero - Brasil, México e Cuba: mulheres protagonistas no meio rural. Revista de Estudos Feministas, set./dez. Florianópolis, 2010.

LIMA, Terezinha Moreira; HIRATA, Helena; NOGUEIRA, Claudia Mazzei; GOMES, Vera Lúcia Batista. Trabalho, gênero e a questão do desenvolvimento. III JORNADA INTERNACIONAL DE POLÍTICAS PÚBLICAS. São Luís: UFMA, 2007.

LOGAN, Robert K. Que é informação?: A propagação da informação na biosfera, na simbolosfera, na tecnosfera. Tradução de Adriana Braga. Rio de Janeiro: Contraponto, 2012.

MELO, Hildete Pereira de; SABBATO, Alberto Di. Divisão sexual do trabalho e pobreza. In:___ Autonomia econômica e empoderamento da mulher: textos acadêmicos. Brasília: Fundação Alexandre de Gusmão, 2011.

NEVES, Magda de Almeida. Desigualdades de gênero e raça no mercado de trabalho: precarização e discriminação salarial. In: Autonomia econômica e empoderamento da mulher: textos acadêmicos. Brasília: Fundação Alexandre de Gusmão, 2011.

OLINTO, Gilda; OLIVEIRA, Zuleika Lopes Cavalcante de. A inserção no trabalho segundo a condição na família: dados da PNAD 2001 para o Brasil urbano.

Gênero e trabalho precário no Brasil. Niterói, v. 5, n. 1, 2004.

Gênero e trabalho precário no Brasil urbano: perspectivas de mudança. XIV ENCONTRO NACIONAL DE ESTUDOS POPULACIONAIS. Caxambú-MG, Brasil, de 20 a 24 de setembro de 2004.

OLINTO, Gilda; MEDEIROS, Ana Ligia Silva. Capital Social e biblioteca pública. Rio de Janeiro, 2013 (publicação no prelo).

PAULILO, Maria Ignez; SILVA, Cristiani Bereta Da. A luta das mulheres agricultoras: entrevista com Dona Adélia Schmitz. Revista de Estudos Feministas, maio/ago. Florianópolis, 2007.

SALES, Celecina de Maria Veras. Mulheres rurais: tecendo novas relações e reconhecendo direitos. Revista de Estudos Feministas, maio/ago. Florianópolis, 2007.

SALVARO, Giovana Ilka Jacinto; LAGO, Mara Coelho de Souza; WOLF, Cristina Scheibe. "Mulheres agricultoras" e "Mulheres camponesas": lutas de gênero, identidades políticas e subjetividades. 2013.

SOARES, Ana Carolina Eiras Coelho. Educação no campo, mulheres e movimentos sociais: espaços de vida, ensinamentos para a transformação social brasileira. (resenha do livro 
"Educação, relações de gênero e movimentos sociais: um diálogo necessário" de Alzira Salete Menegat, Losandro Antonio Tedeschi e Marisa de Fátima Lomba de Farias (Org.). Dourados: UFGD, 2009). Revista de Estudos Feministas, maio./ago. Florianópolis, 2011.

SOARES, Vera. Mulher, autonomia e trabalho. In: Autonomia econômica e empoderamento da mulher: textos acadêmicos. Brasília: Fundação Alexandre de Gusmão, 2011.

SHIRAISHI NETO, Joaquim. "Crise" nos padrões jurídicos tradicionais: o direito em face dos grupos sociais portadores de identidade coletiva. Anais. XIV CONGRESSO NACIONAL DE PESQUISA EM PÓS-GRADUAÇÃO EM DIREITO. Fortaleza, 2005.

VELOSO, Renato. Tecnologia da informação e da comunicação: desafios e perspectivas. São Paulo: Saraiva, 2011. 